\title{
The GERAS Study: A Prospective Observational Study of Costs and Resource Use in Community Dwellers with Alzheimer's Disease in Three European Countries - Study Design and Baseline Findings
}

\author{
Anders Wimo ${ }^{\mathrm{a}}$, Catherine C. Reed ${ }^{\mathrm{b}, *}$, Richard Dodel ${ }^{\mathrm{c}}$, Mark Belger ${ }^{\mathrm{b}}$, Roy W. Jones ${ }^{\mathrm{d}}$, \\ Michael Happich ${ }^{\mathrm{b}}$, Josep M. Argimon ${ }^{\mathrm{e}}$, Giuseppe Bruno ${ }^{\mathrm{f}}$, Diego Novick ${ }^{\mathrm{b}}$, Bruno Vellas ${ }^{\mathrm{g}}$ \\ and Josep Maria Haro ${ }^{\mathrm{h}}$ \\ ${ }^{a}$ KI Alzheimer's Disease Research Center, Department of Neurobiology, Care Sciences and Society, \\ Karolinska Institute, Stockholm, Sweden \\ ${ }^{\mathrm{b}}$ Eli Lilly and Company Limited, Lilly Research Centre, Windlesham, UK \\ ${ }^{\mathrm{c}}$ Department of Neurology, Philipps-University, Marburg, Germany \\ ${ }^{\mathrm{d}}$ RICE - The Research Institute for the Care of Older People, The RICE Centre, Royal United Hospital, Bath, UK \\ ${ }^{\mathrm{e}}$ Divisió d'avaluació, Servei Català de la Salut, Barcelona, Spain \\ ${ }^{\mathrm{f}}$ Department of Neurology and Psychiatry, University of Rome "Sapienza" Rome, Italy \\ ${ }^{\mathrm{g}}$ Gerontopole, Toulouse University Hospital, UMR 1027 INSERM Univeriste Toulouse 3, France \\ ${ }^{\mathrm{h}}$ Parc Santari Sant Joan de Déu, CIBERSAM, Universitat de Barcelona, Sant Boi de Llobregat, Barcelona, Spain
}

\begin{abstract}
To address socioeconomic challenges associated with its increasing prevalence, data are needed on country-level resource use and costs associated with Alzheimer's disease (AD). GERAS is an 18-month observational study being conducted in France, Germany, and the UK (with an 18-month extension in France and Germany), aimed at determining resource use and total costs associated with $\mathrm{AD}$, stratified by $\mathrm{AD}$ severity at baseline. Resource use information and time spent on informal care by non-professional caregivers was obtained using the Resource Utilization in Dementia instrument. Total baseline societal costs were based on four cost components: patient health care costs, patient social care costs, caregiver health care costs, and caregiver informal care costs. Overall, 1,497 community-dwelling patients with AD were analyzed at baseline. Estimated mean monthly total societal costs per patient at baseline differed significantly between groups with mild, moderate, and moderately severe/severe $\operatorname{AD}(p<0.001$ in each country): €1,418,€1,737, and €2,453 in France; $€ 1,312, € 2,412$, and $€ 3,722$ in Germany; and $€ 1,621, € 1,836$, and $€ 2,784$ in the UK, respectively. All cost components except caregiver health care costs increased with $\mathrm{AD}$ severity. Informal caregiver costs were the largest cost component accounting for about half to just over $60 \%$ of total societal costs, depending on country and AD severity group. In conclusion, GERAS study baseline results showed that country-specific
\end{abstract}

\footnotetext{
${ }^{*}$ Correspondence to: Dr. Catherine C. Reed, Global Health Outcomes, Eli Lilly and Company, Erl Wood Manor, Sunninghill Road, Windlesham, Surrey, GU20 6PH, UK. Tel.: +44 1276 483243; Fax: +44 1276 483192; E-mail: reed_catherine@lilly.com.
} 
costs increase with AD severity. Informal care costs formed the greatest proportion of total societal costs, increasing with $\mathrm{AD}$ severity independent of costing method. Longitudinal data will provide information on cost trends with disease progression.

Keywords: Alzheimer's disease, caregivers, cohort study, cost, dementia, Europe, informal care, Mini-Mental State examination, observational study, resource use

\section{INTRODUCTION}

Dementia currently affects about 10 million people across Europe, with a reported prevalence rate of $6.2 \%$ for all those aged 60 years and over [1]. With a growing aging population, the number of people in Europe with dementia is expected to increase to about 14 million in 2030 [1]. Alzheimer's disease (AD), a progressive, neurodegenerative disorder, is the most common cause of dementia, representing up to $75 \%$ of all cases [2]. AD is associated with a social and economic burden, and the provision of care for people with $\mathrm{AD}$ is a complex and costly issue [3-6].

Several studies have provided data on the costs of care associated with AD in different European countries [4, 7-17], but a lack of standardized methodology makes it difficult to compare the results of different studies, and many studies do not have a longitudinal design. Up-to-date, long-term information on country-specific costs of care is needed because care arrangements and resource use patterns change over time, and are dependent on culture and the health and social care systems in each country [4]. Much of the care given to $\mathrm{AD}$ patients in the early stages of the disease is provided informally by non-professional caregivers (mainly family members) [1]. The type and amount of care needed by patients with AD vary as the disease progresses, resulting in an increasing role for caregivers. Recent studies have estimated caregiver costs in various European countries [6, 11-13, 15-19]. However, the societal cost of informal care in different countries remains unclear because of methodological differences in cost calculations (e.g., the types of costs included/excluded and the data used to estimate them) or its frequent exclusion from economic evaluations $[7,20]$. In addition, insufficient information is available on the relationship between $\mathrm{AD}$ severity and cost of care (including informal care).

GERAS is an 18-month observational study being conducted in France, Germany, and the UK (with an 18-month extension period in France and Germany) that aims to assess the country-specific costs and resource use associated with AD for communitydwelling patients and their caregivers, stratified by patients' disease severity at baseline. GERAS aims to address some of the limitations of previous cost studies by using a standardized method for assessing resource use and caregiver time over a longer follow-up period.

The objective of this article is to describe the study design and the baseline findings, especially the country-specific resource use by patients and their caregivers together with estimates of the countryspecific costs associated with $\mathrm{AD}$ at baseline.

\section{SUBJECTS AND METHODS}

\section{Study design and participating centers}

GERAS is an 18-month, multicenter, observational study designed to assess the direct and indirect country costs associated with $\mathrm{AD}$ for patients and their caregivers in France, Germany, and the UK. Patients in France and Germany are being followed up for a further 18 months.

Physicians from the three countries enrolled patients between October 1, 2010 and September 31, 2011. Study centers were mostly specialist secondary care clinics ('memory clinics').

Patients and caregivers were evaluated at baseline and will undergo a maximum of four evaluations during the core study (baseline, 6-, 12-, and 18 months), which will take place during their routine care visits at 6-month intervals ( \pm 6 weeks). In the centers taking part in the extended follow-up, additional evaluations will take place at 24-, 30-, and 36 months.

\section{Study cohort}

Community-dwelling patients (aged $\geq 55$ years) were enrolled in the study if they had probable AD, defined according to the National Institute of Neurological and Communicative Disorders, and Stroke and Alzheimer's Disease and Related Disorders Association (NINCDS-ADRDA) criteria [21], a Mini-Mental State examination (MMSE) [22] score of $\leq 26$, and presented within the normal course of care (i.e., for the diagnosis, treatment, or follow-up care of AD). Patients with a history, clinical signs, or imaging of 
stroke or transient ischemic attack, patients with a history of Parkinson's disease prior to, or at the start of AD onset, and probable Lewy-body disease were excluded from the study, as were those who, at baseline, were participating in an interventional study.

Patients were required to have a caregiver who was willing to participate in the study and to undertake responsibility for the patient for at least six months of the year. This person was defined as an informal carer who, according to the family, was the person (other than a health care professional) who would normally take responsibility for most of the day-to-day decisions and the provision of home care for the patient. Ethical review board approval of the study was obtained in each country according to individual country regulations. The patient (or their legal representative) and caregiver were both required to provide written informed consent prior to enrollment.

Patients were stratified according to disease severity at baseline using MMSE criteria consistent with UK clinical guidelines [23]: 'Mild AD severity' (MMSE 21-26 points); 'Moderate AD severity' (MMSE 15-20 points); 'Moderately severe/severe AD severity' (MMSE $<15$ points). To achieve approximately equal numbers of patients in the three $\mathrm{AD}$ severity groups within each country, the moderately severe/severe $\mathrm{AD}$ group is an oversampled stratum as, based on UK estimates, approximately $12.5 \%$ of patients with AD are categorized as severe [24], and nearly two-thirds of patients with dementia live in the community [24]. There was no requirement for patients to be treated with any specific AD medication at study entry; treatment for AD could be prescribed in the usual way throughout the study, and any treatment decisions were solely at the discretion of the physician and the patient. Information on AD medication, any psychiatric treatment prescribed, as well as medication for co-morbidities was recorded.

\section{Assessments}

Data on cognitive, functional, and behavioral assessments of the patient, health-related quality of life (HRQoL) of the patient and caregiver, and caregiver burden, along with patient and caregiver resource use were collected using an electronic device (CRF Health). Patient and caregiver demographics and baseline characteristics including co-morbidities and medications were collected using an electronic clinical report form. The Resource Utilization in Dementia (RUD) instrument, measuring health care resource utilization for patients and caregivers (e.g., living accommodation, hospitalizations, community care services) and time spent on informal care by caregivers, was administered by the physician, and answered by the caregiver and the $\mathrm{AD}$ patient (as long as disease severity permitted) [25].

Cognitive function was assessed using the MMSE [22] and the cognitive subscale of the Alzheimer's Disease Assessment Scale (ADAS-Cog) [26].

Functional ability was assessed using the Alzheimer's Disease Co-operative Study Activities of Daily Living Inventory (ADCS-ADL) [27, 28]. The range for the total ADCS-ADL score is 0-78, higher scores indicating lower functional impairment. Separate scores for the basic ADLs (range 0-22) and instrumental ADLs (range 0-56) were also computed.

Behavioral and psychological symptoms were assessed using the Neuropsychiatric Inventory (NPI) 12 [29, 30], a caregiver-interview based assessment tool.

HRQoL was evaluated separately in the patient and the caregiver using the EuroQoL-5D (EQ-5D) [31]. This is a standardized instrument used to measure overall health status and is applicable to a wide range of health conditions and treatments. The EQ-5D consists of two parts: (1) health status is classified according to five dimensions of health (mobility, self-care, usual activities, pain/discomfort, and anxiety/depression), from which scores on individual dimensions are recorded, together with a total score that is a summation of individual dimension scores. The standard practice is to use the same tariff in multi-country studies and the UK tariff was used for all three countries to obtain a patient health utility figure-the weighted EQ-5D total health status index score (EQ-5D index) - with a range from 0 (dead) to 1 (perfect health) [32]; (2) a visual analog scale (EQ-VAS) assesses perceived overall health status on a scale from 0 (worst imaginable health state) to 100 (best imaginable health state) [33]. In the GERAS study, the caregiver completed the proxy version of EQ-5D for the patient [34] and the caregiver version for themselves.

\section{Cost estimation}

Baseline cost data were calculated from resource use information obtained from the RUD and from additional data collected from caregivers on treatments, financial assistance, out-of-pocket expenses, and neuropsychological assessments. Monthly costs (2010 values) were estimated by applying countryspecific unit costs of services and products to the recorded health care resource use in the month 
before baseline (Supplementary Table 1; available online: http://dx.doi.org/10.3233/JAD-122392). Costs were calculated by country (no pooled analysis of costs) and stratified by disease severity at baseline.

Costs were broken down into the following components (for full details, see Supplementary Table 1): 1) patient health care costs: including costs of patients' medications (AD medications, antipsychotic/hypnotic medication, medications for co-morbidities), nights in hospital, emergency room visits, and outpatient visits; 2) patient social care costs: including costs of patient living accommodation, community care services, structural adaptations to the patient's living accommodation, consumables, and financial support received; 3) caregiver health care costs: including costs of medications for caregiver medical conditions, caregiver nights in hospital, emergency room visits, and outpatient visits; and 4) caregiver informal care costs: including costs of caregiver time and of the caregiver missing work. The costs for these four cost components were combined to give the total societal costs.

The primary analysis of costs (i.e., the base case) was based on a lost productivity approach, with patient and caregiver health care costs, and patient social care costs calculated as described above. Informal care costs were calculated using the higher cost of either the cost of caregiver time spent on the patient or the total cost of caregiver missing work to care for the patient (the same unit cost was applied to both items, see Supplementary Table 1). The problems in costing informal care and the approach of using different unit costs for caregivers based on the working status of the caregiver have been discussed previously [35]. Caregiver time was calculated as the number of hours for basic living activities plus the number of hours of instrumental activities (number of hours for 'supervision' was excluded). For working caregivers, the unit cost for caregiver time was the value of lost production time, with the cost based on the national average wage per country population (see Supplementary Table 1). For non-working caregivers, the unit cost for caregiver time was the value of lost leisure time, and this was costed at $35 \%$ of the national average wage per country population as in previous studies $[12,36]$ (see Supplementary Table 1 for costs used). Informal caregiver time, lost working days, and reduction in caregiver working hours were converted to "hours in the past month" to be consistent with all of the other resource use measures included in the cost calculations.

Two sensitivity analyses were carried out using alternative values for costing informal care, as these were considered to have a higher level of uncertainty. Sensitivity analysis 1 used the same unit costs for caregiver time as the base case above, but included supervision time in the calculation of caregiver time. Sensitivity analysis 2 was based on full replacement costs, where the costs for caregiver time were assigned a value equivalent to the costs for a professional carer (with hourly costs based on the national minimum wage or the wage for a basic carer as available in each country). In this analysis of costs, caregiver time included supervision time and the same unit cost for caregiver time was applied for all caregivers (i.e., working status was not taken into account) in each country (2010 values): France, $€ 8.95$; Germany, $€ 9.61$; UK, $€ 6.80(£ 5.83)^{1}$. The sources of all unit costs are given in Supplementary Table 1.

\section{Sample size}

To provide meaningful data for each participating country, and because significant variation was expected between countries, the sample size was determined based on the number of patients required for each country and took into account potential drop-outs using the rate from a previous observational study [37]. We therefore assumed that $30 \%$ of patients would be lost to follow-up during an 18-month follow-up period and that $20 \%$ of patients would be lost to follow-up each year over a three-year follow-up period. We also assumed that costs would be exponentially distributed and that equal numbers of patients would be enrolled in each of the three severity groups (based on MMSE scores). Based on these assumptions, we calculated that a minimum of 600 patients per country (200 in each severity group) was required to obtain a $95 \%$ confidence interval of $\pm 10 \%$ of the mean cost estimate.

\section{Statistical analysis}

The analysis reported is exploratory only; no confirmatory statistical tests were performed. Confidence intervals (95\% level, two-sided) and statistical tests (two-sided level of 5\%) are descriptive. The full analysis set (FAS) was used for the analyses; FAS included all patients with $\mathrm{AD}$ and their caregivers who provided consent to release information and who fulfilled the study entry criteria. Analysis was performed overall and by country and stratified by disease severity at baseline (defined by MMSE scores as described previ-

\footnotetext{
${ }^{1}$ Conversion rate: $£ 1=€ 1.1661$ (calculated as the monthly exchange rate average for 2010; http://www.X-rates.com/d/EUR/GB P/hist2010.html, Accessed on June 22, 2012.
} 
ously). The results presented are based on non-missing data.

Demographics and baseline characteristics were summarized using descriptive statistics and were based on non-missing observations. Comparisons between AD severity groups used Cochran-Mantel-Haenszel $(\mathrm{CMH})$ tests for categorical data, stratified by country, and ANOVA with independent factors for MMSE severity and country for continuous data. For the resource utilization variables there was a high number of zero events (e.g., number of hospital visits), therefore $p$-values for $\mathrm{AD}$ severity groups were taken from an inflated Poisson regression model with AD severity group and country as factors.

Cost data are usually not normally distributed and parametric tests may therefore not be valid. However, when the sample size is large, the distribution of the mean is normal regardless of the distribution of the individual level data; therefore, the parametric $t$-test is sufficient and nonparametric methods for cost analysis [38] are not necessary. This was the case in the current analyses; bootstrapping of total costs are not presented because the sample size was large enough to have had minimal impact on the results. Thus, it was deemed appropriate to perform and present testing using parametric $t$-tests, and $p$-values are presented accordingly. As an alternative for the test of significance for total societal cost, we performed a General Linear Model using the gamma distribution to account for skewness in the total cost data. Based on this model, the cost estimates are identical and $p$ values for the primary analyses are still all highly significant between severity groups $(p<0.0001)$.

For this baseline analysis, the number of missing patients for the cost analysis was minimal $(<1 \%)$. We have assumed these patient data are missing at random and would have a negligible impact on the total cost estimates; therefore, no imputation of missing data has been performed.

ANOVA $p$-values with AD severity group as the factor were reported for all costs (assuming central limit theory due to sample size). For the UK cost data, statistical testing was performed on the data in pounds sterling, but the results are presented in euros for ease of comparison between countries. The conversion rate used was $£ 1=€ 1.1661$ (calculated as the monthly exchange rate average for 2010$)^{2}$.

All data were analyzed using SAS software, version 9.2 (SAS Institute, Cary, North Carolina, USA).

\footnotetext{
2 http://www.X-rates.com/d/EUR/GBP/hist2010.html, Accessed on June 22, 2012.
}

\section{RESULTS}

\section{Investigators and patients}

Of the 94 investigators involved in the study, most were specialists, predominantly psychiatrists (34.8\%), neurologists $(32.6 \%)$, and geriatricians $(30.3 \%)$. The specialty of the participating investigators varied by country: in France, $63.6 \%$ were geriatricians; in Germany, $48.6 \%$ were neurologists and $40.5 \%$ were psychiatrists; and in the UK, $78.9 \%$ were psychiatrists specializing in the care of elderly people and $15.8 \%$ were geriatricians. Most investigators $(68.5 \%)$ worked in public practice, and $64.0 \%$ of practices were in an urban location (with at least 2,000 inhabitants).

The investigators enrolled 1,532 patients overall, but $35(2 \%)$ patients were excluded from the analysis for the following reasons (more than one reason applied in some cases): age not given $(n=13)$, MMSE missing or $>26(n=22)$, and stroke reported at baseline visit $(n=9)$. Thus, a total of 1,497 patients were suitable for analysis. Of these 1,497 patients, 567 (37.9\%) had mild AD, $472(31.5 \%)$ had moderate $\mathrm{AD}$, and 458 $(30.6 \%)$ had moderately severe/severe $\mathrm{AD}$; the number of patients in each severity group by country is given in Table 1.

For this baseline analysis, only 9 of the 1,497 patients $(<1 \%)$ had missing data and were excluded from the estimates of total societal costs: 2 from France, 2 from Germany, and 5 from the UK.

\section{Baseline characteristics}

Table 1 summarizes the baseline characteristics of the patients involved in this study. Overall, the proportion of women in each group was higher as $\mathrm{AD}$ severity increased. Across all three countries, the main caregiver was the patient's spouse, with the highest percentage of this being in the mild AD severity group (Table 2).

The majority of patients (77.5\% overall) were taking an acetylcholinesterase (AChE) inhibitor at the baseline assessment. Overall, the proportion of patients taking memantine increased with the severity of $\mathrm{AD}$, but memantine use clearly differed between countries with around a third of patients (over all AD severity groups) in Germany and France and $4.2 \%$ of patients in the UK taking memantine (Table 1).

The majority of patients $(73.5 \%$ overall) had at least one comorbidity with hypertension, depression, and hypercholesterolemia the most commonly reported comorbid conditions (data not shown). 
Table 1

Patient characteristics at baseline: overall and country-specific data

\begin{tabular}{|c|c|c|c|c|c|c|}
\hline \multirow[t]{2}{*}{ Characteristic } & \multirow[t]{2}{*}{ Country } & \multicolumn{4}{|c|}{ AD severity } & \multirow[t]{2}{*}{ Overall population } \\
\hline & & Mild & Moderate & Moderately severe/severe & $p$ value & \\
\hline \multirow[t]{4}{*}{ Number of patients } & Overall & 567 & 472 & 458 & & 1497 \\
\hline & France & 138 & 136 & 145 & & 419 \\
\hline & Germany & 228 & 157 & 167 & & 552 \\
\hline & UK & 201 & 179 & 146 & & 526 \\
\hline \multirow[t]{4}{*}{ Age, years (mean [SD]) } & Overall & $77.3(6.97)$ & $77.8(7.95)$ & $77.6(8.17)$ & NS & $77.6(7.66)$ \\
\hline & France & $79.3(5.93)$ & $78.7(7.35)$ & $80.2(7.03)$ & NS & $79.4(6.81)$ \\
\hline & Germany & $74.7(6.89)$ & $75.9(8.10)$ & $75.4(8.00)$ & NS & $75.2(7.59)$ \\
\hline & UK & $78.8(6.85)$ & $78.9(7.97)$ & $77.6(8.69)$ & NS & $78.5(7.79)$ \\
\hline \multirow[t]{4}{*}{ Gender ( $\%$ female $)$} & Overall & 47.8 & 57.2 & 61.1 & $* *$ & 54.8 \\
\hline & France & 54.3 & 67.6 & 64.8 & NS & 62.3 \\
\hline & Germany & 42.1 & 53.5 & 56.9 & $*$ & 49.8 \\
\hline & UK & 49.8 & 52.5 & 62.3 & NS & 54.2 \\
\hline \multirow{4}{*}{$\begin{array}{l}\text { Time since diagnosis, } \\
\text { years (mean [SD]) }\end{array}$} & Overall & $1.7(2.00)$ & $2.1(2.04)$ & $3.1(2.40)$ & $* *$ & $2.2(2.22)$ \\
\hline & France & $2.1(2.30)$ & $2.2(2.29)$ & $3.2(2.46)$ & $* *$ & $2.5(2.41)$ \\
\hline & Germany & $1.3(1.58)$ & $2.0(1.99)$ & $3.0(2.51)$ & $* *$ & $2.0(2.14)$ \\
\hline & UK & $1.8(2.12)$ & $2.0(1.88)$ & $3.1(2.20)$ & NS & $2.2(2.13)$ \\
\hline \multirow{4}{*}{$\begin{array}{l}\text { Marital status, } \\
\text { married/cohabiting }(\%)\end{array}$} & Overall & 74.8 & 68.2 & 72.5 & NS & 72.0 \\
\hline & France & 68.1 & 63.2 & 66.9 & NS & 66.1 \\
\hline & Germany & 79.4 & 75.8 & 73.1 & NS & 76.4 \\
\hline & UK & 74.1 & 65.2 & 77.4 & NS & 72.0 \\
\hline \multirow[t]{4}{*}{ Living alone, own home (\%) } & Overall & 18.6 & 22.8 & 11.2 & $* *$ & 17.7 \\
\hline & France & 21.5 & 26.4 & 16.1 & NS & 21.2 \\
\hline & Germany & 19.3 & 19.5 & 9.7 & $* *$ & 16.6 \\
\hline & $\mathrm{UK}$ & 15.7 & 23.0 & 8.1 & $*$ & 16.1 \\
\hline \multirow{4}{*}{$\begin{array}{l}\text { Patients taking an } \\
\text { acetylcholinesterase } \\
\text { inhibitor }(\%)^{1}\end{array}$} & Overall & 78.8 & 79.9 & 73.4 & NS & 77.5 \\
\hline & France & 81.9 & 83.8 & 75.2 & NS & 80.2 \\
\hline & Germany & 73.7 & 73.2 & 61.1 & NS & 69.7 \\
\hline & $\mathrm{UK}$ & 82.6 & 82.7 & 85.6 & NS & 83.5 \\
\hline \multirow[t]{4}{*}{ Patients taking memantine $(\%)^{1}$} & Overall & 11.6 & 18.6 & 33.6 & $* *$ & 20.6 \\
\hline & France & 13.8 & 26.5 & 55.9 & $* *$ & 32.5 \\
\hline & Germany & 19.7 & 28.7 & 35.9 & $* *$ & 27.2 \\
\hline & UK & 1.0 & 3.9 & 8.9 & $*$ & 4.2 \\
\hline
\end{tabular}

$1 \%$ values calculated based on total population of severity group. $* p<0.05, * * p<0.001$ for comparison between AD severity groups (ANOVA for continuous variables and Cochran-Mantel-Haenszel test for categorical variables). 'Mild' AD (Alzheimer's disease) severity = MMSE (MiniMental State examination) 21-26 points; 'Moderate' AD severity = MMSE 15-20 points; 'Moderately severe/severe' AD severity = MMSE $<15$ points. (NS, not significant $[p \geq 0.05]$ ).

Table 3 presents the cognitive, functional, and behavioral scores at baseline for the overall patient population, and shows increased impairment and poorer functioning and $\mathrm{HRQOL}$ as $\mathrm{AD}$ severity increases (see Supplementary Table 2 for countryspecific data).

\section{Resource utilization}

Resource use in the month before the baseline visit by patients and caregivers is shown in Tables 4 and 5 , respectively. Patient use of health care resources (e.g., number of nights in hospital, outpatient visits, requirement for home aid/orderly, and need for day care) were all significantly higher as AD severity increased across the groups $(p<0.001$ overall) (Table 4$)$. There was very little patient use of the emergency room $(97.1 \%$ of patients in the overall cohort had no emergency room visits, and there was a maximum of two emergency room visits in any of the AD severity groups; data not shown) and most caregivers (97.7\%) had no nights in hospital. Caregiver resource use for the overall cohort did not differ across the AD severity groups (Table 5). Overall, 355 (23.8\% of) caregivers were working for pay. The majority of non-working caregivers had reached retirement age $(74.1 \%)$ or had taken early retirement (7.8\%; not AD-related) (data not shown). Caregivers who were employed worked an average of 31.4 hours/week, although nearly a quarter had reduced their work hours to care for the patient (Table 5). A small proportion of caregivers were being paid to care for their AD patient in France and Germany (none in the UK). French caregivers were being paid for more hours than German caregivers.

Figure 1 shows a clear relationship between increasing severity of $\mathrm{AD}$ and increased informal caregiver 
Table 2

Caregiver characteristics at baseline: overall and country-specific data

\begin{tabular}{|c|c|c|c|c|c|c|}
\hline \multirow[t]{2}{*}{ Characteristic } & \multirow[t]{2}{*}{ Country } & \multicolumn{4}{|c|}{ AD severity } & \multirow[t]{2}{*}{ Overall population } \\
\hline & & Mild & Moderate & Moderately severe/severe & $p$ value & \\
\hline \multirow[t]{4}{*}{ Number of caregivers } & Overall & 567 & 472 & 458 & & 1497 \\
\hline & France & 138 & 136 & 145 & & 419 \\
\hline & Germany & 228 & 157 & 167 & & 552 \\
\hline & $\mathrm{UK}$ & 201 & 179 & 146 & & 526 \\
\hline \multirow[t]{4}{*}{ Age, years (mean $[\mathrm{SD}]$ ) } & Overall & $68.1(11.60)$ & $66.7(11.70)$ & $67.0(12.85)$ & NS & $67.3(12.03)$ \\
\hline & France & $68.6(11.94)$ & $66.3(12.37)$ & $68.8(12.77)$ & NS & $67.9(12.39)$ \\
\hline & Germany & $66.6(11.19)$ & $66.8(11.05)$ & $64.0(13.00)$ & NS & $65.9(11.76)$ \\
\hline & UK & $69.4(11.70)$ & $66.9(11.79)$ & $68.7(12.21)$ & NS & $68.3(11.90)$ \\
\hline \multirow[t]{4}{*}{ Gender ( $\%$ female $)$} & Overall & 68.6 & 64.4 & 58.3 & $*$ & 64.1 \\
\hline & France & 70.1 & 58.8 & 58.6 & NS & 62.4 \\
\hline & Germany & 71.1 & 66.9 & 63.6 & NS & 67.6 \\
\hline & UK & 64.7 & 66.5 & 52.1 & $*$ & 61.8 \\
\hline \multicolumn{7}{|l|}{ Caregiver relationship (\%) } \\
\hline Spouse & Overall & 70.7 & 63.1 & 62.9 & $*$ & 65.9 \\
\hline Child & & 23.5 & 28.8 & 29.8 & & 27.1 \\
\hline Other & & 5.8 & 8.1 & 7.2 & & 7.0 \\
\hline Spouse & France & 65.0 & 56.6 & 63.4 & NS & 61.7 \\
\hline Child & & 30.7 & 36.0 & 31.7 & & 32.8 \\
\hline Other & & 4.4 & 7.4 & 4.8 & & 5.5 \\
\hline Spouse & Germany & 72.8 & 69.4 & 58.8 & $*$ & 67.6 \\
\hline Child & & 19.7 & 20.4 & 33.3 & & 24.0 \\
\hline Other & & 7.5 & 10.2 & 7.9 & & 8.4 \\
\hline Spouse & UK & 72.1 & 62.6 & 67.1 & $*$ & 67.5 \\
\hline Child & & 22.9 & 30.7 & 24.0 & & 25.9 \\
\hline Other & & 5.0 & 6.7 & 8.9 & & 6.6 \\
\hline
\end{tabular}

* $p<0.05$ for comparison between AD severity groups (ANOVA for continuous variables and Cochran-Mantel-Haenszel test for categorical variables). 'Mild' AD (Alzheimer's disease) severity = MMSE (Mini-Mental State examination) 21-26 points; 'Moderate' AD severity = MMSE 15-20 points; 'Moderately severe/severe' AD severity = MMSE $<15$ points. (NS, not significant $[p \geq 0.05]$ ).

Table 3

Patient-reported outcomes at baseline presented as overall data for all three countries combined (see Supplementary Table 2 for countryspecific data)

\begin{tabular}{|c|c|c|c|c|c|}
\hline & \multicolumn{4}{|c|}{ AD severity } & \multirow[t]{2}{*}{ Overall population } \\
\hline & Mild & Moderate & Moderately severe/severe & $p$ value & \\
\hline Number of patients & 567 & 472 & 458 & & 1497 \\
\hline MMSE & $23.3(23.2 ; 23.5)$ & $17.9(17.8 ; 18.1)$ & $9.5(9.1 ; 9.9)$ & 1 & $17.4(17.1 ; 17.7)$ \\
\hline ADL - basic & $19.8(19.6 ; 20.1)$ & $18.3(17.9 ; 18.6)$ & $13.2(12.7 ; 13.8)$ & $* *$ & $17.3(17.1 ; 17.6)$ \\
\hline ADL - instrumental & $38.6(37.6 ; 39.5)$ & $29.9(28.8 ; 31.1)$ & $16.6(15.5 ; 17.8)$ & $* *$ & $29.2(28.4 ; 29.9)$ \\
\hline ADL - total & $58.5(57.3 ; 59.6)$ & $48.3(46.9 ; 49.7)$ & $30.0(28.4 ; 31.6)$ & $* *$ & $46.6(45.6 ; 47.6)$ \\
\hline ADAS- $\operatorname{cog} 11$ & $19.0(18.5 ; 19.5)$ & $27.1(26.4 ; 27.8)$ & Not applied & $* *$ & $22.7(22.2 ; 23.2)$ \\
\hline NPI 12 total & $10.2(9.3 ; 11.1)$ & $14.3(13.1 ; 15.4)$ & $22.0(20.2 ; 23.8)$ & $* *$ & $15.1(14.3 ; 15.9)$ \\
\hline EQ-5D index (proxy) ${ }^{2}$ & $0.71(0.69 ; 0.73)$ & $0.64(0.62 ; 0.67)$ & $0.51(0.48 ; 0.54)$ & $* *$ & $0.63(0.61 ; 0.64)$ \\
\hline EQ-VAS (proxy) & $66.0(64.5 ; 67.5)$ & $64.6(62.8 ; 66.3)$ & $58.7(56.6 ; 60.8)$ & $* *$ & $63.3(62.3 ; 64.3)$ \\
\hline
\end{tabular}

Data are presented as means $(95 \% \mathrm{CI})$ unless otherwise indicated. ${ }^{1}$ No statistical analysis performed. ${ }^{2}$ Presented to two decimal places to more clearly distinguish utility scores between severity groups. $* * p<0.001$ for comparison between AD severity groups (ANOVA). 'Mild' AD severity = MMSE 21-26 points; 'Moderate' AD severity = MMSE 15-20 points; 'Moderately severe/severe' AD severity = MMSE <15 points. Reduced functioning is indicated by lower scores for MMSE and ADL, and higher scores for ADAS-cog11; increased impairment is indicated by higher scores for NPI 12 total; reduced quality of life is indicated by lower scores for EQ-5D. (AD, Alzheimer's disease; ADAS-Cog11, Alzheimer's disease assessment scale - cognitive subscale; ADL, activities of daily living; EQ-5D, EuroQoL-5D; EQ-VAS, EQ-5D visual analog scale; MMSE, Mini-Mental State examination; NPI, neuropsychiatric inventory).

time spent on basic activities of daily living, instrumental activities of daily living and supervision (data from RUD questionnaire); each time component and the overall monthly caregiver time were significantly different across AD severity groups in each country $(p<0.001$ for overall monthly caregiver time) (Fig. 1).
Costs

Estimated mean monthly total societal costs per patient at baseline differed significantly between groups with mild, moderate, and moderately severe/severe $\mathrm{AD}(p<0.001$ in each country): $€ 1,418$ 
Table 4

Resource use by patients in the month prior to baseline: country-specific data and overall for all three countries combined

\begin{tabular}{|c|c|c|c|c|c|c|}
\hline \multirow[t]{2}{*}{ Resource use by patients } & \multirow[t]{2}{*}{ Country } & \multicolumn{4}{|c|}{ AD severity } & \multirow{2}{*}{$\begin{array}{c}\text { Overall } \\
\text { population }\end{array}$} \\
\hline & & Mild & Moderate & $\begin{array}{l}\text { Moderately } \\
\text { severe/severe }\end{array}$ & $p$ value & \\
\hline \multirow[t]{4}{*}{ Total number of nights in hospital } & Overall & $0.2(0.1 ; 0.3)$ & $0.5(0.2 ; 0.7)$ & $0.6(0.3 ; 1.0)$ & $* *$ & $0.4(0.3 ; 0.6)$ \\
\hline & France & $0.1(-0.0 ; 0.3)$ & $0.5(-0.1 ; 1.0)$ & $0.4(0.1 ; 0.8)$ & $* *$ & $0.3(0.1 ; 0.6)$ \\
\hline & Germany & $0.4(0.1 ; 0.7)$ & $0.9(0.3 ; 1.6)$ & $1.3(0.4 ; 2.2)$ & $* *$ & $0.8(0.5 ; 1.2)$ \\
\hline & UK & $0.0(-0.0 ; 0.1)$ & $0.1(-0.0 ; 0.1)$ & $0.1(-0.7 ; 0.2)$ & $* *$ & $0.0(0.0 ; 0.1)$ \\
\hline \multirow{4}{*}{ Outpatient visits } & Overall & $3.4(2.6 ; 4.1)$ & $3.2(2.5 ; 3.9)$ & $4.0(3.0 ; 5.0)$ & $* *$ & $3.5(3.1 ; 4.0)$ \\
\hline & France & $3.9(2.4 ; 5.3)$ & $3.2(2.6 ; 3.9)$ & $5.7(3.4 ; 8.0)$ & $* *$ & $4.3(3.4 ; 5.2)$ \\
\hline & Germany & $4.3(3.0 ; 5.7)$ & $4.4(2.9 ; 6.0)$ & $4.1(2.8 ; 5.4)$ & $* *$ & $4.3(3.5 ; 5.1)$ \\
\hline & UK & $2.0(1.0 ; 3.0)$ & $2.1(1.0 ; 3.3)$ & $2.3(0.8 ; 3.8)$ & $* *$ & $2.1(1.4 ; 2.8)$ \\
\hline \multirow[t]{4}{*}{ District nurse $^{1}$} & Overall & $2.8(11.73)$ & $3.7(18.01)$ & $5.1(14.21)$ & NS & $3.8(14.73)$ \\
\hline & France & $6.4(15.70)$ & $7.3(16.77)$ & $9.1(17.02)$ & NS & $7.6(16.52)$ \\
\hline & Germany & $2.7(11.77)$ & $4.4(26.57)$ & $6.0(16.39)$ & NS & $4.2(18.44)$ \\
\hline & UK & $0.6(7.07)$ & $0.3(2.12)$ & $0.2(0.81)$ & NS & $0.4(4.56)$ \\
\hline \multirow[t]{4}{*}{ Home aid/orderly ${ }^{1}$} & Overall & 3.4 (15.09) & $3.1(9.94)$ & $6.6(16.54)$ & $* *$ & $4.3(14.25)$ \\
\hline & France & $6.9(21.91)$ & $4.6(10.02)$ & $8.5(13.35)$ & NS & $6.7(15.91)$ \\
\hline & Germany & $0.5(2.53)$ & $0.8(2.78)$ & $1.6(5.42)$ & $*$ & $1.0(3.72)$ \\
\hline & UK & $4.3(17.08)$ & $3.9(13.10)$ & $10.4(24.52)$ & $*$ & $5.9(18.53)$ \\
\hline \multirow[t]{4}{*}{ Food delivery ${ }^{1}$} & Overall & $2.8(38.43)$ & $3.3(46.23)$ & $1.6(12.73)$ & NS & $2.6(35.82)$ \\
\hline & France & $7.9(76.96)$ & $8.3(85.70)$ & $2.8(20.39)$ & NS & $6.2(66.78)$ \\
\hline & Germany & $1.0(4.96)$ & $1.4(5.77)$ & $1.7(8.94)$ & NS & $1.3(6.60)$ \\
\hline & UK & $1.5(9.72)$ & $1.1(5.31)$ & $0.2(1.28)$ & NS & $1.0(6.80)$ \\
\hline \multirow[t]{4}{*}{ Day care $^{1}$} & Overall & $0.6(2.60)$ & $0.8(2.58)$ & $1.9(4.18)$ & $* *$ & $1.1(3.21)$ \\
\hline & France & $0.9(2.57)$ & $0.8(2.20)$ & $1.7(3.54)$ & $*$ & $1.2(2.87)$ \\
\hline & Germany & $0.1(1.08)$ & $0.5(1.96)$ & $1.6(4.82)$ & $* *$ & 0.7 (2.99) \\
\hline & UK & $1.0(3.59)$ & $1.1(3.23)$ & $2.2(3.99)$ & $*$ & $1.4(3.62)$ \\
\hline \multirow{4}{*}{$\begin{array}{l}\text { Transportation } \\
\text { (public paid) }^{1}\end{array}$} & Over & & & & & $07(349)$ \\
\hline & France & $1.7(7.50)$ & $1.1(3.19)$ & $1.1(3.46)$ & NS & $1.3(5.09)$ \\
\hline & Germany & $0.2(1.89)$ & $0.2(1.35)$ & $0.8(3.29)$ & $*$ & $0.4(2.30)$ \\
\hline & UK & $0.4(1.89)$ & $0.5(1.88)$ & $1.2(4.43)$ & $*$ & $0.6(2.85)$ \\
\hline
\end{tabular}

Data are presented as means $(95 \% \mathrm{CI})$ unless otherwise indicated. $* p<0.05, * * p<0.001$ for comparison between AD severity groups (zero inflated Poisson regression model) ${ }^{1}$ Mean (SD) number of times within last month prior to baseline visit; $95 \%$ CI not available. 'Mild' AD severity = MMSE 21-26 points; 'Moderate' AD severity = MMSE 15-20 points; 'Moderately severe/severe' AD severity = MMSE <15 points. (AD, Alzheimer's disease; MMSE, Mini-Mental State examination; NS, not significant [ $p \geq 0.05]$ ).

(SD 1,336), €1,737 (SD 1,733), and €2,453 (SD 2,250 ) in France; $€ 1,312$ (SD 1,628), €2,412 (SD 2,890 ), and $€ 3,722$ (SD 4,178) in Germany; and $€ 1,621$ (SD 1,731), €1,836 (SD 1,506), and €2,784 (SD 1,760) in the UK, respectively. Figure 2 shows the mean costs per month at baseline for each of the four cost components (patient and caregiver health care costs, patient social care costs, and caregiver informal care costs) by AD severity group in France, Germany, and the UK. In each country, the monthly cost for caregiver informal care was the largest cost component and increased with increasing disease severity across the AD severity groups $(p<0.001)$. In Germany and the UK (but not France), patient social care costs also increased with increasing AD severity $(p<0.001)$. Direct medical costs for patients and for caregivers did not differ across the AD severity groups in any of the countries. Total monthly societal costs of $\mathrm{AD}$ for the overall sample were calculated as $€ 1,881$
(SD 1,869), €2,349 (SD 3,114), and €2,016 (SD 1,731) for France, Germany, and the UK, respectively; in each country, these costs differed significantly between $\mathrm{AD}$ severity groups $(p<0.001$; see Fig. 2$)$. The total monthly societal costs are not the sum of the four individual cost components because the estimate for each cost component was based on non-missing data whereas the total cost was calculated for those with data for all four cost components, so the number of patients included in each cost calculation differs slightly. However, the number of patients with missing data only ranged between 0 and 2 for each cost calculation for each level of disease severity in each country.

\section{Sensitivity analysis}

When the cost analysis included caregiver supervision time (sensitivity analysis 1), informal caregiver 
Table 5

Resource use by caregivers and variables related to caregiver time in the month prior to baseline: country-specific data and overall for all three countries combined

\begin{tabular}{|c|c|c|c|c|c|c|}
\hline \multirow[t]{2}{*}{ Variable } & \multirow[t]{2}{*}{ Country } & \multicolumn{4}{|c|}{ AD severity } & \multirow[t]{2}{*}{ Overall population } \\
\hline & & Mild & Moderate & Moderately severe/severe & $p$ value & \\
\hline \multirow[t]{4}{*}{ Number of caregivers } & Overall & 567 & 472 & 458 & & 1497 \\
\hline & France & 138 & 136 & 145 & & 419 \\
\hline & Germany & 228 & 157 & 167 & & 552 \\
\hline & UK & 201 & 179 & 146 & & 526 \\
\hline \multirow[t]{4}{*}{ Caregivers working for pay (\%) } & Overall & 23.7 & 25.2 & 22.4 & NS & 23.8 \\
\hline & France & 21.2 & 26.5 & 17.2 & NS & 21.5 \\
\hline & Germany & 27.6 & 28.0 & 30.3 & NS & 28.5 \\
\hline & UK & 20.9 & 21.8 & 18.5 & NS & 20.5 \\
\hline \multirow{4}{*}{$\begin{array}{l}\text { Time in paid work, for caregivers } \\
\text { who are working, hours/week }\end{array}$} & Overall & $32.5(29.9 ; 35.1)$ & $30.2(27.6 ; 32.8)$ & $31.4(28.5 ; 34.4)$ & NS & $31.4(29.9 ; 33.0)$ \\
\hline & France & $39.1(35.1 ; 43.2)$ & $35.1(31.0 ; 39.2)$ & $37.4(33.6 ; 41.3)$ & NS & $37.1(34.8 ; 39.3)$ \\
\hline & Germany & $32.4(28.5 ; 36.0)$ & $29.4(25.4 ; 33.4)$ & $31.2(26.9 ; 35.5)$ & NS & $31.2(28.9 ; 33.4)$ \\
\hline & UK & $28.1(22.5 ; 33.8)$ & $26.5(21.3 ; 31.7)$ & $26.4(19.8 ; 33.1)$ & NS & $27.1(23.9 ; 30.3)$ \\
\hline \multirow{4}{*}{$\begin{array}{l}\text { Caregivers who reduced usual } \\
\text { work hours, if applicable }(\%)\end{array}$} & Overall & 20.9 & 24.4 & 25.5 & NS & 23.4 \\
\hline & France & 13.8 & 22.2 & 8.0 & NS & 15.6 \\
\hline & Germany & 27.0 & 27.3 & 34.0 & NS & 29.3 \\
\hline & UK & 16.7 & 23.1 & 25.9 & NS & 21.3 \\
\hline \multirow{4}{*}{$\begin{array}{l}\text { Work loss, if caregiver is working, } \\
\text { hours/week }\end{array}$} & Overall & $10.9(5.7 ; 16.2)$ & $13.3(8.2 ; 18.5)$ & $11.3(6.6 ; 16.0)$ & NS & $11.9(9.1 ; 14.7)$ \\
\hline & France & $6.0(-1.0 ; 13.0)$ & $15.1(3.3 ; 27.0)$ & $2.5(-16.6 ; 21.6)$ & NS & $10.7(3.8 ; 17.6)$ \\
\hline & Germany & $8.8(3.8 ; 13.7)$ & $9.2(3.5 ; 14.8)$ & $10.0(4.4 ; 15.6)$ & NS & $9.3(6.4 ; 12.2)$ \\
\hline & UK & $19.0(-0.9 ; 38.9)$ & $17.3(3.7 ; 31.0)$ & $16.9(4.7 ; 29.0)$ & NS & $17.7(10.3 ; 25.1)$ \\
\hline \multirow{4}{*}{$\begin{array}{l}\text { Number of missed working days } \\
\text { in last month (for working } \\
\text { caregivers) }\end{array}$} & Overall & $0.9(0.5 ; 1.2)$ & $1.0(0.5 ; 1.6)$ & $1.1(0.5 ; 1.8)$ & NS & $1.0(0.7 ; 1.3)$ \\
\hline & France & $0.7(0.4 ; 1.1)$ & $0.5(0.2 ; 0.8)$ & $0.8(0.2 ; 1.3)$ & NS & $0.6(0.4 ; 0.9)$ \\
\hline & Germany & $1.0(0.4 ; 1.6)$ & $1.0(0.5 ; 1.5)$ & $1.0(0.3 ; 1.7)$ & NS & $1.0(0.7 ; 1.4)$ \\
\hline & UK & $0.7(0.2 ; 1.2)$ & $1.6(0.0 ; 3.2)$ & $1.7(-0.4 ; 3.8)$ & NS & $1.3(0.5 ; 2.0)$ \\
\hline \multirow{4}{*}{$\begin{array}{l}\text { Caregivers paid to care for } \\
\text { patient, if applicable }(\%)\end{array}$} & Overall & 3.7 & 3.4 & 9.8 & NS & 5.4 \\
\hline & France & 10.3 & 5.6 & 8.0 & NS & 7.8 \\
\hline & Germany & 3.2 & 4.5 & 16.0 & $*$ & 7.6 \\
\hline & UK & 0 & 0 & 0 & NS & 0 \\
\hline \multirow{4}{*}{$\begin{array}{l}\text { Amount of time caregiver paid } \\
\text { to care for patient, if applicable } \\
\text { (hours/week) }\end{array}$} & Overall & $17.0(15.23)$ & $18.8(8.54)$ & $15.5(15.07)$ & NS & $16.6(13.38)$ \\
\hline & France & $20.7(18.48)$ & $17.5(3.54)$ & $36.0(19.80)$ & NS & $24.1(15.77)$ \\
\hline & Germany & $11.5(12.02)$ & $20.0(14.14)$ & $10.4(9.27)$ & NS & $12.2(9.98)$ \\
\hline & UK & 0 & 0 & 0 & NS & 0 \\
\hline \multirow[t]{4}{*}{ Number of outpatient visits } & Overall & $2.3(1.3 ; 3.4)$ & $1.4(1.1 ; 1.6)$ & $2.2(1.5 ; 2.9)$ & NS & $2.0(1.5 ; 2.4)$ \\
\hline & France & $2.2(1.2 ; 3.2)$ & $1.4(1.0 ; 1.7)$ & $2.3(0.8 ; 3.8)$ & NS & $2.0(1.4 ; 2.6)$ \\
\hline & Germany & $1.9(1.5 ; 2.2)$ & $2.0(1.4 ; 2.6)$ & $2.8(1.5 ; 4.1)$ & NS & $2.2(1.8 ; 2.6)$ \\
\hline & UK & $2.9(0.1 ; 5.7)$ & $0.8(0.6 ; 1.0)$ & $1.4(0.7 ; 2.1)$ & NS & $1.8(0.7 ; 2.9)$ \\
\hline
\end{tabular}

Data are presented as means $(95 \% \mathrm{CI})$ unless otherwise indicated. ${ }^{1}$ Based on reported number of hours lost per week in last month prior to baseline visit by caregivers who were working. ${ }^{2}$ For the cost calculations, these were converted to "hours in the past month" to be consistent with the other resource use measures. ${ }^{3}$ Mean (SD) number of times within last month prior to baseline visit; $95 \%$ CI not available. $* p=0.026$ for comparison between AD severity groups (zero-inflated Poisson regression model), 'Mild' AD severity = MMSE (Mini-Mental State examination) 21-26 points; 'moderate' AD (Alzheimer's disease) severity = MMSE 15-20 points; 'moderately severe/severe' AD severity = MMSE <15 points. (NS, not significant $[p \geq 0.05])$.

costs were higher in each country relative to the primary analysis, which was reflected in higher mean total monthly societal costs of AD. In France, mean total monthly societal costs were $€ 2,012$ (SD 2,118), $€ 2,490$ (SD 2,353), and $€ 3,963$ (SD 2,920) for the groups with mild, moderate, and moderately severe/severe $\mathrm{AD}$, respectively ( $p<0.001$ between $\mathrm{AD}$ severity groups). In Germany, mean total monthly societal costs were $€ 1,819$ (SD 2,707), $€ 3,189(3,553)$, and $€ 5,592$ (SD 4,983) for mild, moderate, and moderately severe/severe AD, respectively $(p<0.001$ between $\mathrm{AD}$ severity groups). In the UK, mean total monthly societal costs were $€ 2,048$ (SD 2,172), $€ 2,519$ (SD 2,261 ), and $€ 3,999$ (SD 2,787) for mild, moderate, and moderately severe/severe $\mathrm{AD}$, respectively $(p<0.001$ between $\mathrm{AD}$ severity groups).

For the sensitivity analysis with full replacement costs (including country-specific costs for supervision time and professional care based on the minimum wage; sensitivity analysis 2), the caregiver informal care costs were increased relative to the primary analysis but were lower than in the first sensitivity analysis; the pattern of change was the same for all three countries. For France, the total monthly societal costs of 


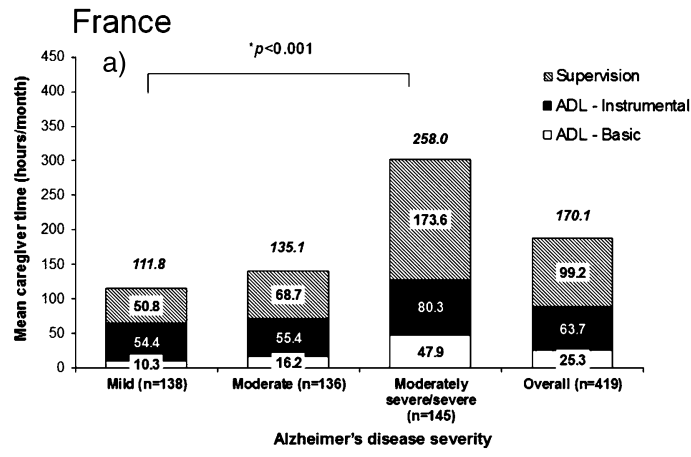

Germany
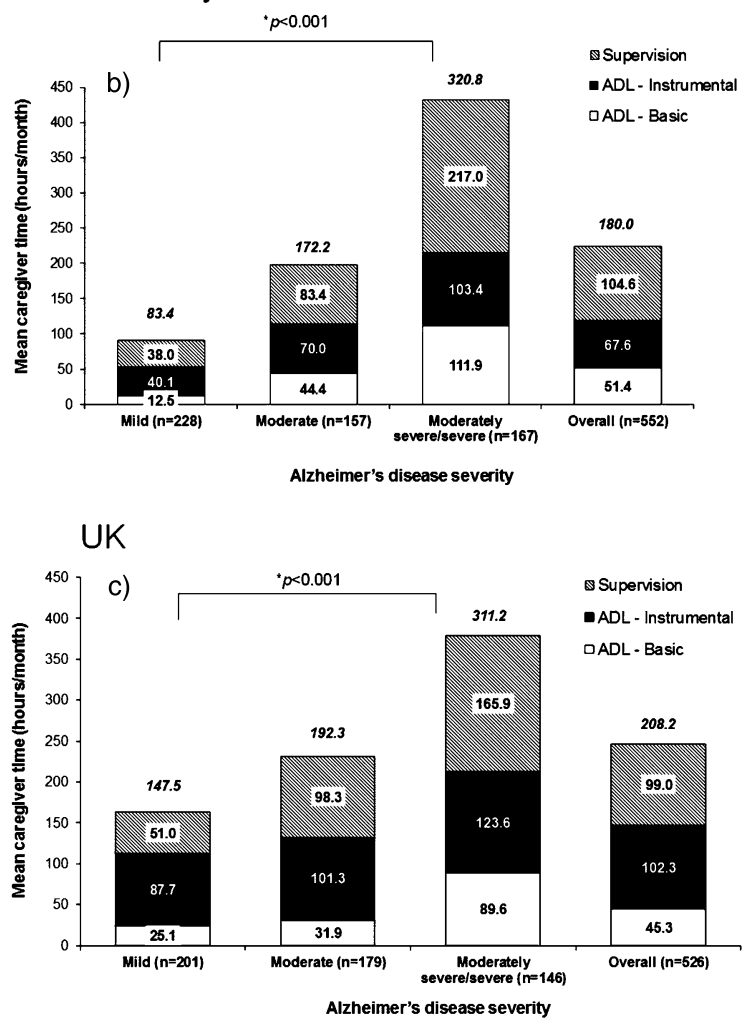

Fig. 1. Informal caregiver time (including supervision) spent on patients (hours/month) at baseline for a) France b) Germany, and c) UK. * $p$ value for comparison between severity groups (ANOVA) of mean overall monthly caregiver time (value in italics above each column). Note: this value is based on data provided for the last month prior to the baseline visit and is not the sum of the individual components; it is calculated for those who have data for all three time components. Each of the time components is calculated for those with non-missing data, so the patient numbers may differ. ADL, activities of daily living.

$\mathrm{AD}$ in this sensitivity analysis were $€ 1,817, € 2,303$, and $€ 3,730$ for mild, moderate, and moderately severe/severe AD, respectively ( $p<0.001$ between AD severity groups). For Germany, the total monthly societal costs of AD were $€ 1,616, € 3,033$, and $€ 5,073$ for mild, moderate, and moderately severe/severe $\mathrm{AD}$, respectively ( $p<0.001$ between $\mathrm{AD}$ severity groups). For the UK, the total monthly societal costs of AD were $€ 1,769, € 2,216$, and $€ 3,470$ for mild, moderate, and moderately severe/severe $\mathrm{AD}$, respectively $(p<0.001$ between $\mathrm{AD}$ severity groups).

\section{DISCUSSION}

The GERAS study provides unique information on societal costs of $\mathrm{AD}$ in community-dwelling patients both across different severity levels and between countries. The baseline cost data described show that increasing severity of $\mathrm{AD}$ among community-dwelling patients was associated with rising costs in all three countries (France, Germany, UK). The mean monthly total societal cost per patient almost doubled between the mild and moderately severe/severe groups in France and the UK, and increased almost three-fold in Germany. These costs were higher in Germany than in France or the UK for both moderate AD and moderately severe/severe $\mathrm{AD}$. The increase in the cost of $\mathrm{AD}$ with increasing severity is consistent with previous reports $[9,10,14,16]$ and, with increasing $\mathrm{AD}$ prevalence, the rising costs will impact on payers and providers of health care. The high costs of providing long-term care in nursing homes [17, 39] provides the impetus to find treatments that delay disease progression and enable patients to live at home for as long as possible.

Currently, new treatments need to demonstrate cost-effectiveness over standard care (e.g. the UK), innovation (e.g., France and Germany), or a favorable impact on budget (e.g., Spain) in order to achieve reimbursement. Availability of country-specific data on characteristics, resource use and cost in 'reallife' patients is sporadic across Europe, highlighting GERAS as a source of important data in these three large European countries. In particular, with the inclusion of moderately severe/severe $\mathrm{AD}$ patients, the longitudinal data will enable a description of cost trends throughout the progression of the disease.

In this study of community-dwelling patients with $\mathrm{AD}$, the cost of caregiver informal care was the largest cost component at baseline (see Fig. 2), accounting for about half to just over $60 \%$ of the total monthly societal costs, depending on country and $\mathrm{AD}$ severity group, and increasing with $\mathrm{AD}$ severity. If the longitudinal data support this finding, it will be important to understand what drives these informal care costs in each 


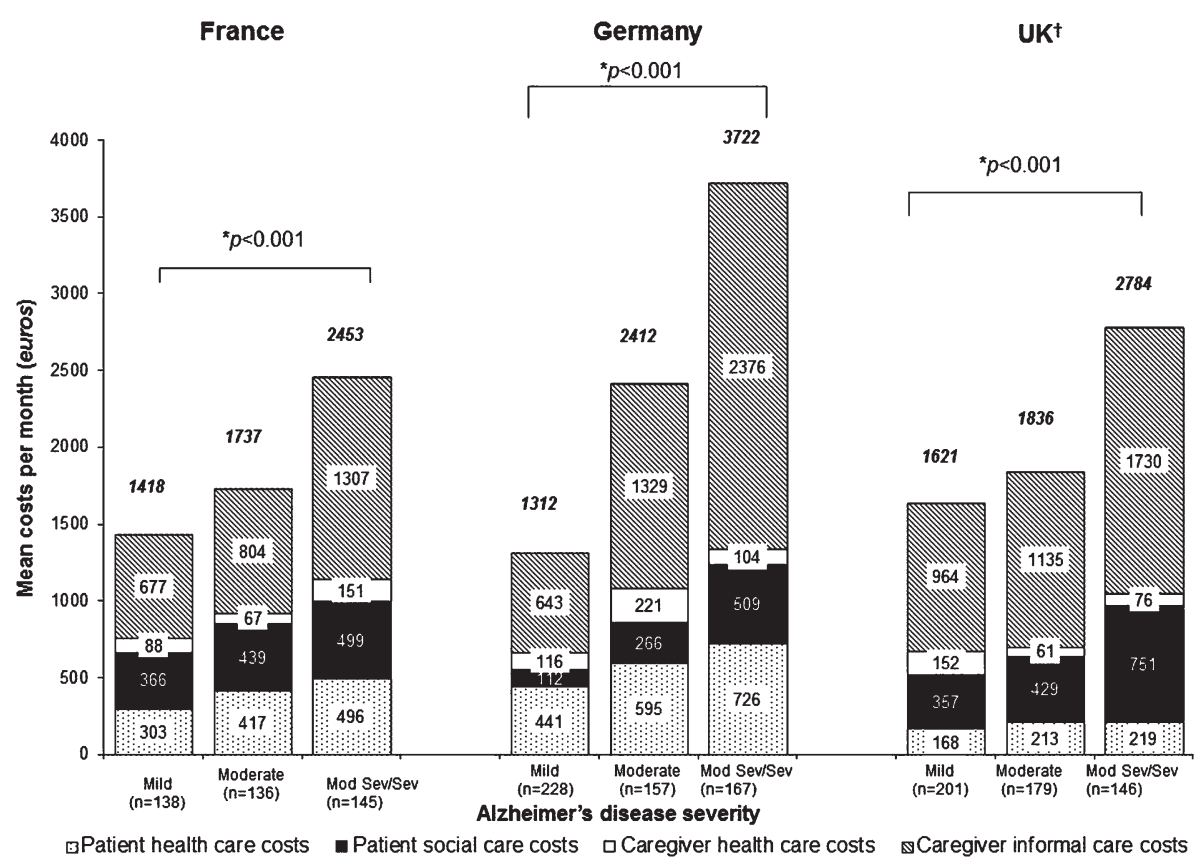

Fig. 2. Monthly mean costs (euros, $€$ ) at baseline for each of the four cost components associated with Alzheimer's disease (AD) by AD severity (mild, moderate, moderately severe/severe) for France, Germany, and UK. * $p$ value for comparison between severity groups (ANOVA) of total monthly societal costs (value in italics above each column). ${ }^{\dagger}$ UK costs were converted from pounds sterling to euros using the conversion rate $£ 1=$ euros 1.1661. Note: supervision time is excluded from caregiver time in the caregiver informal care cost calculation. The value above each column is the mean total monthly societal costs. This value is not the sum of the individual components; it is calculated for those who have data for all four cost components. Each of the individual cost components is calculated for those with non-missing data (the number with missing data ranged between 0 and 2 for each cost component and for each level of disease severity). The $n$ value given under each column is the total number of patients in each cohort. Mod Sev/Sev, moderately severe/severe.

country so that appropriate resources can be allocated to provide support and interventions for caregivers; this may improve the health and well-being of both caregivers and patients, and could buffer the cost of care for the health system by delaying institutionalization [3].

Resource utilization by patients at baseline was low (see Table 4) due to the one-month data collection period and this was reflected in the relatively low patient health care and social care costs, which together accounted for less than half of the total costs in each $\mathrm{AD}$ severity group in each country. The one-month data collection period impacted less frequent events, such as hospitalizations and secondary care appointments, with a bias toward under-reporting likely leading to an underestimation of direct health care costs. However, if outpatient visits usually take place shortly after a hospitalization, data capture in the 1-month period may over-represent outpatient visits and lead to an overestimation of direct costs. Follow-up data will provide more accurate assessment of resource use over longer time periods and enable a better understanding of how dementia care patterns differ between countries. Figure 2 shows that patient health care costs in the UK were lower at all levels of AD severity, compared with the other two countries. These between-country differences may be due to differences in resource use and in the unit costs applied for health care resources used (see Supplementary Table 1). Additionally, medication costs were generally lower in the UK than in France or Germany. Our findings are in line with the different patterns of health and social care costs reported for these three countries by Luengo-Fernandez et al. [15].

We used the RUD to measure resource utilization and caregiver time in all three countries, and this standardized instrument has been shown to accurately assess time spent by caregivers giving informal care to $\mathrm{AD}$ patients [40]. Prospectively collected data on resource use from longitudinal studies, such as the GERAS study, are needed to see whether changes in patients' activities of daily living, identified as the most important predictor of societal costs of care for community-dwelling patients across different countries [12], are associated with changes in costs with disease progression.

The RUD also collects caregiver resource use data which are included in the societal viewpoint. Although 
caregiver resource use cannot always be classified as a consequence of $\mathrm{AD}$, it was a very small component of total costs in each AD severity group at baseline in the GERAS study. Changes in caregiver resource use over time will be monitored to understand the impact of increasing AD severity on caregiver resource use.

Our results indicate that the main driver for differences in country total societal costs is likely to be informal care and how it is measured and given a value. Since unpaid care has no market value, there is a considerable variability in the costing of informal caregiver time [7, 41]. Methods such as a lost productivity approach or a replacement cost approach are commonly used. Caregiver time costs were based on each country's national average hourly wage, which was lower in the UK than in France and Germany (see Table 1). Despite this, the informal care costs for patients with mild $\mathrm{AD}$ severity were highest in the UK (see Fig. 2), reflecting the higher number of hours per month spent caring for this patient group in the UK, compared with France and Germany (see Fig. 1). For patients with moderate $A D$ or moderately severe/severe $\mathrm{AD}$, informal care costs were highest in Germany and lowest in France. Since the unit costs applied for informal care were similar in France and Germany, the differences in informal care costs are likely due to country differences in caregiver estimates of time spent caring.

Quantifying caregiver time is problematic and the assessment of aspects of caregiver time, such as instrumental activities of daily living, varies across cultures [4]. In the primary cost analysis, we excluded supervision time because caregivers find it difficult to quantify exactly how many hours they spend on supervision, since it can be combined with activities of daily living, such as watching television [19], and estimates vary substantially between countries [42]. Nevertheless, we found that supervision time is a significant part of caregivers' activities and was the largest component of overall caregiver time in both France and Germany, but accounted for slightly less caregiver time than ADL-instrumental in the UK (see Fig. 1).

Giving a value to informal care time is also problematic because not all caregivers make economic sacrifices to provide informal care for people with dementia living at home [43]. For this reason, we applied different costs to informal care time for working and non-working caregivers in the primary analysis and these hourly costs are, thus, weighted to represent the proportions of those contributing to care. Variables related to caregiver time among working caregivers (23.8\% of the overall population), as seen in Table 5 , suggested a loss of earnings from employment because of their role as a caregiver. As most of the non-working caregivers had reached retirement age or taken early retirement, we assumed that only their leisure time was restricted due to care provision. Valuation of leisure time is more problematic, but one frequently used approach is to use travel time estimates from which the figure of $35 \%$ of the country-specific average wage was derived $[12,36]$.

Since a wide range of methods have been used to estimate costs in $\mathrm{AD}$ [44] and there is no consensus on the best method to use for costing informal care time [4], we performed two sensitivity analyses that both included supervision time in the calculation of informal care time. As expected, informal care costs were higher in all three countries when supervision time was included in the lost productivity cost calculation (sensitivity analysis 1 ). Consequently, the total societal costs were higher than in the base-case analysis. Likewise, the cost of caregiver informal care increased when it was calculated using full replacement costs (sensitivity analysis 2), but was lower than in sensitivity analysis 1 . Thus, despite using different methods to estimate its value, informal caregiver time was the main cost driver in community-dwelling patients with AD. However, the methods used to measure caregiver time and calculate costs together with the specific unit costs applied in each country can considerably influence the differences in costs between countries.

There were some differences between countries in the characteristics of the GERAS population at baseline. Overall, patients in France and the UK were older than those in Germany; this enrollment of different ages may reflect the between-country differences in investigator specialty. However, within each country, there was no difference in patient age across AD severity groups. There were fewer women recruited into the study (55\% overall) than might be expected because the incidence of $\mathrm{AD}$ among persons aged $60-80$ years is higher in women than in men [45]. Previous observational studies of patients with $\mathrm{AD}$ living in the community found about two-thirds were women [42, 46, 47, 48].

The study has several limitations that potentially introduce selection bias and influence the external validity of the study. The participating patients were a clinic-based cohort (not a population-based sample) who use formal care (e.g., sought and received a diagnosis, attend memory clinics) but were still living in the community, with an informal caregiver and felt able to participate in the study. This will limit the external validity of the results as the sample from 
this prospective observational study will not be fully representative of all $\mathrm{AD}$ patients living in the community. Also, because the study centers were mostly specialist centers (memory clinics), the frequency of users of $\mathrm{AD}$ medications (AChE inhibitors and/or memantine) may be an overestimate.

Another limitation of the study is that the stratification of costs by disease severity was based on MMSE, and different cut-offs for mild, moderate, and moderately severe/severe disease have been used in other studies [9], making comparisons difficult. We used a MMSE $<15$ to define moderately severe/severe AD, which was a pragmatic approach to enable us to enroll sufficient patients with more severe disease living in the community. Although 185 patients $(40 \%$ of the moderately severe/severe group) had a MMSE score of $<10$, the cut-offs used in the GERAS study may bias the moderately severe/severe AD group toward less affected people, so it may not be representative of patients with more severe AD living in the community, and the costs for this group are likely to have been underestimated.

The differences in patient characteristics between AD severity groups in each country may have confounding effects on resource utilization and associated costs, but these have not been taken into account in the current analysis. Finally, cultural differences between countries regarding the care of patients with $\mathrm{AD}$, as well as differences in health care systems, means that the resource utilization and cost data from the three countries in the GERAS study may be problematic to extrapolate to other countries.

In conclusion, the baseline findings from the GERAS study clearly showed that the country-specific total societal costs increase as AD severity worsens. Total societal costs were higher in Germany than in France or the UK for both moderate $\mathrm{AD}$ and moderately severe/severe $\mathrm{AD}$, but in all countries caregiver informal care costs were the major cost component at all levels of $\mathrm{AD}$ severity. The longitudinal nature of this study will provide important information on disease progression, resource use estimates and costs for modeling the cost-effectiveness of AD treatments, including interventions to slow disease progression and contribute to the discussion on the international transferability of cost and utilization figures.

\section{ACKNOWLEDGMENTS}

This study was supported by Eli Lilly and Company. The authors wish to thank all investigators who participated in the study. The authors would like to acknowledge Dr. Deirdre Elmhirst and Dr. Claire Lavin (Rx Communications, Mold, UK) for medical writing assistance with the preparation of this article, funded by Eli Lilly and Company.

Authors' disclosures available online (http://www.jalz.com/disclosures/view.php?id=1729).

\section{SUPPLEMENTARY MATERIAL}

Supplementary material can be found here: http:// dx.doi.org/10.3233/JAD-122392

\section{REFERENCES}

[1] Alzheimer's Disease International (2009) World Alzheimer Report 2009. The Global Prevalence of Dementia, pp. 25-44, ADI, London, http://www.alz.co.uk/research/worldreport, October 10, 2012, Accessed on October 29, 2012.

[2] Qiu C, Kivipelto M, von Strauss E (2009) Epidemiology of Alzheimer's disease: Occurrence, determinants and strategies toward intervention. Dialogues Clin Neurosci 11, 111-128.

[3] Nourhashemi F, Olde Rikkert MG, Burns A, Winblad B, Frisoni GB, Fitten J, Vellas B (2010) Follow-up for Alzheimer patients: European Alzheimer disease consortium position paper. $J$ Nutr Health Aging 14, 121-130.

[4] Wimo A, Prince M Alzheimer's Disease International (2010) World Alzheimer Report 2010. The Global Economic Impact of Dementia. ADI, London, http://www.alz.co.uk/research/ files/WorldAlzheimerReport2010.pdf, Accessed on October 29, 2012.

[5] Wimo A, Winblad B, Jönsson L (2010) The worldwide societal costs of dementia: Estimates for 2009. Alzheimers Dement 6, 98-103.

[6] Wimo A, Jönsson L, Gustavsson A, McDaid D, Ersek K, Georges J, Gulácsi L, Karpati K, Kenigsberg P, Valtonen H (2011) The economic impact of dementia in Europe in 2008 - cost estimates from the Eurocode project. Int $J$ Geriatr Psychiatr 26, 825-832.

[7] Jönsson L, Wimo A (2009) The cost of dementia in Europe. A review of the evidence and methodological considerations. Pharmacoeconomics 27, 391-403.

[8] Coduras A, Rabasa I, Frank A, Bermejo-Pareja F, LópezPousa S, López-Arrieta J-M, Del Llano J, León T, Rejas J (2010) Prospective one-year cost-of-illness study in a cohort of patients with dementia of Alzheimer's disease type in Spain: The ECO Study. J Alzheimers Dis 19, 601-615.

[9] Mauskopf J, Racketa J, Sherrill E (2010) Alzheimer's disease: The strength of association of costs with different measures of disease severity. J Nutr Health Aging 14, 655-663.

[10] Quentin W, Riedel-Heller SG, Luppa M, Rudolph A, König H-H (2010) Cost-of-illness studies of dementia: A systematic review focusing on stage dependency of costs. Acta Psychiatr Scand 121, 243-259.

[11] Gustavsson A, Cattelin F, Jönsson L (2011) Costs of care in a mild-to-moderate Alzheimer clinical trial sample: Key resources and their determinants. Alzheimers Dement 7, 466473.

[12] Gustavsson A, Brinck P, Bergvall N, Kolasa K, Wimo A, Winblad B, Jönsson L (2011) Predictors of costs of care in 
Alzheimer's disease: A multinational sample of 1222 patients. Alzheimers Dement 7, 318-327.

[13] Handels RLH, Wolfs CAG, Aalten P, Verhey FRJ, Severens JL (2013) Determinants of care costs of patients with dementia or cognitive impairment. Alzheimer Dis Assoc Disord 27, 30-36.

[14] Leicht H, Heinrich S, Heider D, Bachmann C, Bickel H, van den Bussche H, Fuchs A, Luppa M, Maier W, Mösch E, Pentzek M, Rieder-Heller SG, Tebarth F, Werle J, Weyerer $\mathrm{S}$, Wiese B, Zimmermann T, König H-H, for the AgeCoDe study group (2011) Net costs of dementia by disease stage. Acta Psychiatr Scand 124, 384-395.

[15] Luengo-Fernandez R, Leal J, Gray AM (2011) Cost of dementia in the pre-enlargement countries of the European Union. $J$ Alzheimers Dis 27, 187-196.

[16] Mesterton J, Wimo A, By A, Langworth S, Winblad B, Jönsson L (2010) Cross sectional observational study on the societal costs of Alzheimer's disease. Curr Alzheimer Res 7, 358-367.

[17] Reese JP, Hessmann P, Seeberg G, Henkel D, Hirzmann P, Rieke J, Baum E, Dannhoff F, Müller MJ, Jessen F, Geldsetzer M-B, Dodel R (2011) Cost of care of patients with Alzheimer's disease: Clinical predictors in German health care settings. J Alzheimers Dis 27, 723-736.

[18] Lindholm C, Gustavsson A, Jönsson L, Wimo A (2012) Costs explained by function rather than diagnosis - results from the SNAC Nordanstig elderly cohort in Sweden. Int J Geriatr Psychiatry 28, 454-462.

[19] Schwarzkopf L, Menn P, Kunz S, Holle R, Lauterberg J, Marx P, Mehlig H, Wunder S, Leidl R, Donath C, Graessel E (2011) Costs of care for dementia patients in community setting: An analysis for mild and moderate disease stage. Value Health 14, 827-835.

[20] De Meijer C, Brouwer W, Koopmanschap M, van den Berg B, van Exel J (2010) The value of informal care - a further investigation of the feasibility of contingent valuation in informal caregivers. Health Economics 19, 755-771.

[21] McKhann G, Drachman D, Folstein M, Katzman R, Price D, Stadlan EM (1984) Clinical diagnosis of Alzheimer's disease: Report of the NINCDS-ADRDA Work Group under the auspices of Department of Health and Human Services Task Force on Alzheimer's Disease. Neurology 34, 939-944.

[22] Folstein MF, Folstein SE, McHugh PR (1975) "Mini-mental state." A practical method for grading the cognitive state of patients for the clinician. J Psychiatric Res 2, 189-198.

[23] National Institute of Health and Clinical Excellence (2011) NICE technology appraisal guideline 217. Donepezil, galantamine, rivastigmine and memantine for the treatment of Alzheimer's disease. http://www.nice.org.uk/guidance/ TA217. Accessed on November 19, 2012.

[24] Dementia UK (2007) A report into the prevalence and cost of dementia prepared by the Personal Social Services Research Unit (PSSRU) at the London School of Economics and the Institute of Psychiatry at King's College London, for the Alzheimer's Society. Alzheimer's Society, London, http:// www.alzheimers.org.uk/site/scripts/download_info.php?file ID=2, Accessed on October 23, 2012.

[25] Wimo A, Wetterholm AL, Mastey V, Winblad B (1998) Evaluation of resource utilization and caregiver time in anti-dementia drug trials a quantitative battery. The Health Economics of Dementia, Wimo A, Jonsson B, Karlsson G, Eds. John Wiley and Sons, London, pp. 465-499.

[26] Rosen WG, Mohs RC, Davis KL (1984) A new rating scale for Alzheimer's disease. Am J Psychiatry 141, 1356-1364.

[27] Galasko D, Bennett D, Sano M, Ernesto C, Thomas R, Grundman M, Ferris S, the ADCS (1997) An inventory to assess activities of daily living for clinical trials in Alzheimer's disease. Alzheimer Dis Assoc Disord 11, S33-S39.

[28] Galasko D, Schmitt F, Thomas R, Jin S, Bennett D, Ferris S, for the Alzheimer's disease cooperative study (2005) Detailed assessment of activities of daily living in moderate to severe Alzheimer's disease. J Int Neuropsychol Soc 11, 446-453.

[29] Cummings JL, Mega M, Gray K, Rosenberg-Thompson S, Carusi DA, Gornbein J (1994) The neuropsychiatric inventory: Comprehensive assessment of psychopathology in dementia. Neurology 44, 2306-2314.

[30] Cummings JL (1997) The Neuropsychiatric Inventory: Assessing psychopathology in dementia patients. Neurology 48(Suppl 6), 10-16.

[31] Kind P (1996) The EuroQol instrument: An index of health-related quality of life. In Quality of Life and Pharmacoeconomics in Clinical Trials, 2nd edition, Spilker B, Ed. Lippincott-Raven Publishers, Philadelphia, pp. 191-201.

[32] Szende A, Oppe M, Devlin N, Eds. (2007) EQ-5D value sets: Inventory, comparative review and user guide. Series: EuroQol Group Monographs, Vol 2, Springer, the Netherlands.

[33] The EuroQol, Group (1990) Euro-QoL - a new facility for the measurement of health-related quality of life. Health Policy 16, 199-208.

[34] The EuroQol Group (2012) Proxy Paper: EQ-5D-3L, http://www.euroqol.org/eq-5d-products/eq-5d-31/proxypaper.html, Accessed on October 30, 2012.

[35] Karlsson G, Wimo A, Jönsson B, Winblad B (1998) Methodological issues in health economic studies of dementia. In The Health Economics of Dementia, Wimo A, Karlsson G, Jönsson B, Winblad B, Eds. Wiley, London, pp. 161-169.

[36] Johannesson M, Borgquist L, Jönsson B, Råstam L (1991) The costs of treating hypertension - an analysis of different cut-off points. Health Policy 18, 141-150.

[37] Coley N, Gardette V, Toulza O (2008) Predictive factors of attrition in a cohort of Alzheimer disease patients. Neuroepidemiology 31, 69-79.

[38] Nixon R, Wonderling D, Grieve R (2010) Non-parametric methods for cost-effectiveness analysis: The central limit theorem and the bootstrap compared. Health Econ 19, 316-333.

[39] Schwarzkopf L, Menn P, Leidl R, Wunder S, Mehlig H, Marx P, Graessel E, Holle R (2012) Excess costs of dementia disorders and the role of age and gender - an analysis of German health and long-term care insurance claims data. $B M C$ Health Services Research 12, 165, http://www.biomedcentral. com/1472-6963/12/165, Accessed on October 29, 2012.

[40] Wimo A, Jönsson L, Zbrozek A (2010) The Resource Utilization in Dementia (RUD) instrument is valid for assessing informal care time in community-living patients with dementia. J Nutr Health Aging 14, 685-690.

[41] Gustavsson A, Jönsson L, McShane R, Boada M, Wimo A, Zbrozek AS (2010) Willingness-to-pay for reductions in care need: Estimating the value of informal care in Alzheimer's disease. Int J Geriatr Psychiatry 25, 622-632.

[42] Gustavsson A, Jönsson L, Rapp T, Reynish E, Ousset PJ, Andrieu S, Cantet C, Winblad B, Vellas B, Wimo A, the ICTUS Study Group (2010) Differences in resource use and costs of dementia care between European countries: Baseline data from the ICTUS study. J Nutr Health Aging 14, 648-654.

[43] Connolly S, Gillespie P, O'Shea E, Cahill S, Pierce M (2012) Estimating the economic and social costs of dementia in Ireland. Dementia. doi: 10.1177-1471301212442453

[44] Costa N, Derumeaux H, Rapp T, Garnualt V, Ferlicoq L, Gillette S, Andrieu S, Vellas B, Lamure M, Grand A, 
Molinier L (2012) Methodological considerations in cost of illness studies on Alzheimer disease. Health Econ Rev 2, 18 doi: 10.1186/2919-1991-2-18

[45] Vina J, Lloret A (2010) Why women have more Alzheimer's disease than men: Gender and mitochondrial toxicity of amyloid-beta peptide. J Alzheimers Dis 20(Suppl 2), S527S553.

[46] Jönsson L, Eriksdotter Jönhagen M, Kilander L, Soininen H, Hallikainen M, Waldemar G, Nygaard H, Andreasen N Winblad B, Wimo A (2006) Determinants of costs of care for patients with Alzheimer's disease. Int J Geriatr Psychiatry 21, 449-459.
[47] Reynish E, Cortes F, Andrieu S, Cantet C, Olde Rikkert M, Melis R, Forelich L, Frisoni GB, Jonsson L, Visser PJ, Ousset PJ, Vellas B, ICTUS Study Group (2007) The ICTUS study: A prospective longitudinal observational study of 1,380 AD patients in Europe. Neuroepidemiology 29, 29-38.

[48] Froelich L, Andreasen N, Tsolaki M, Foucher A, Kavanagh S, van Baelen B, Schwalen S (2009) Long-term treatment of patients with Alzheimer's disease in primary and secondary care: Results from an international survey. Curr Med Res Opin 25, 3059-3068. 